\title{
Suburban waterfront with ecological and recreational function: planning based on network analysis
}

\author{
Natalia Fumagalli, Claudia Colombo, Paolo Stefano Ferrario, Giulio Senes, \\ Alessandro Toccolini \\ Department of Agricultural and Environmental Sciences, University of Milan, Italy
}

\begin{abstract}
Urban fringe areas have multiple land uses and are places where sections of waterway, together with fragmented areas of natural vegetation, are often found passing through urban areas, transportation routes and gradually expanding rural areas. These overlapping functions are often the cause of an extremely disorderly landscape devoid of guiding connotative elements. In this context, the waterfront can be a guiding element for the redevelopment of the fringe areas between cities and the countryside. The purpose of this paper is the definition of a methodology for planning a suburban waterfront with an ecological function and bicycle paths for recreational use. The evaluation phases for resources and planning, conducted with tools for network analysis, have identified potential corridors based on current land uses and have addressed the issue of bicycle paths on an inter-municipal scale. The methodology is proposed for regional level planning and the validation of the method was achieved through its application to the stretch of the Lambro River between Monza Park and the city of Milan in the North of Italy.
\end{abstract}

\section{Introduction}

Water is essential for life and for the development of all human activity so urban settlements have always evolved in close proximity to water. Over time, the increasing potential of the water supplies and changes in social and economic systems have, in some cases, separated towns from water. These riparian zones, both in central and in more peripheral areas

\footnotetext{
Correspondence: Natalia Fumagalli, Department of Agricultural and Environmental Sciences, University of Milan, via Celoria 2, 20133 Milan, Italy.

Tel.: +39.02.50316850 - Fax: +39.02 .50316845$

E-mail: natalia.fumagalli@unimi.it
}

Key words: land use planning, ecological network, geographical information systems.

Received for publication: 26 July 2013.

Accepted for publication: 30 November 2013.

(C) Copyright N. Fumagalli et al., 2013

Licensee PAGEPress, Italy

Journal of Agricultural Engineering 2013; XLIV:183

doi:10.4081/jae.2013.183

This article is distributed under the terms of the Creative Commons Attribution Noncommercial License (by-nc 3.0) which permits any noncommercial use, distribution, and reproduction in any medium, provided the original author(s) and source are credited. of the borders between towns and the countryside, have been abandoned. This has been a result of the growth of other city waterfronts that were originally in the countryside but that are now included in the urban fringes. To try to contain these phenomena, many cities have carried out projects to rehabilitate abandoned areas by creating waterfronts (Breen and Rigby, 1997; Bunce and Desfor, 2007).

The term waterfront means the border area between land and water (rivers, lakes, sea, etc.). However, it can also be used to indicatxe the areas affected by redevelopment close to water zones and used to help create environments for multiple uses. There are different types of waterfront that have their own distinctive characteristics. The main distinction is made between urban and suburban waterfronts.

In urban areas, the term waterfront is associated with specific sites that can be used to recreate physical, visual and auditory contact between water and people. In rural areas, this term is replaced by greenway or blueway, when a linear view of connection is favoured over a more intermittent one (Fisher et al., 2004). There is, in fact, a substantial relationship between waterfronts and greenways, as both perform functions of environmental restoration and an ecological connection between Man and Nature, and the specificity of the waterfront as a meeting point between land and water (Ahern, 1995; Turner, 1998; Toccolini and Fumagalli, 2007).

In addition, the vegetation and water found in the areas of intervention perform important functions. Water is essential for animal and plant life. It promotes biodiversity, helps freshen the air in the summer, masks noise pollution, and is attractive to the eye. Vegetation helps regulate water temperature and water flow, filters nutrients, provides a habitat for animals and plants, and improves the quality of the surrounding environment (Baschak and Brown, 1995).

These sites are environments that have been recreated for the public. They allow people who visit them to participate in different aquatic and terrestrial activities. The most common aquatic activities that people can participate in are fishing, swimming and canoeing, while landbased activities are represented by hiking, walking, cycling, horse riding, sports and games, concerts and events (Flink and Searns, 1993).

Urban fringe includes multiple land uses: fragmented areas of natural vegetation (with or without water courses), transportation routes and urban areas (decreasing as one passes from the city to the countryside) and expanding rural areas (in the opposite direction).

This overlap of functions often results in an extremely disorderly landscape devoid of guiding connotative elements and rich in residual spaces (Senes et al., 2008).

In this context, the waterfront can be a guiding element for the regeneration of the border areas between cities and the countryside (Bueno et al., 1995; Ben Harman and Low Choy, 2011).

In urban planning, the small streams that flow through these areas are often indicated in a general way as the axes for the completion of the ecological network to be protected and promoted, without a detailed map identifying the most important areas and land uses. The purpose of our paper is to develop a methodology based on the use of geographical information systems (GIS) and Network Analysis for 
planning suburban waterfronts with both recreational and ecological function. The ecological function is fulfilled by existing natural areas that have to be connected and requalified. The recreational function is fulfilled by paths crossing these areas that allow people to enjoy the area along the waterfront. It can be used at a regional level to complete the green infrastructure network (Regione Lombardia, 2010).

The network analysis and graph theory provide powerful tools and methods for analysing ecological networks. Several graph-theoretic metrics related to classical network analysis problems had been developed and tested and ecologically interpreted (Bunn et al., 2000). In graph-theory, a graph presents nodes connected by links. To define the best connections, network analysis tools measure the distances between nodes.

The graph-theory models can be divided into binary and probability models (Urban and Keitt, 2001). Using binary models, it is only possible to analyse if there is a link or not, while probability models allow us to analyse the existing situation (if there are any links or not) and to evaluate each specific patch.

The distance between the nodes can be represented as edge-to-edge interpatch distance, as Euclidian distance, or as least-cost path. The different patches can be ranked according to their importance (Urban and Keitt, 2001) and natural and man-made barriers and breaks can be weighed. They can be used as evaluation tools in the planning process.

In combination with cost-distance modelling (Zetterberg et al., 2010) and improved knowledge about species preferences for different land uses, the tools are helpful to evaluate the value of the ecological landscape and find appropriate solutions in the landscape planning process. In this paper, we decided to use these instruments in a suburban area of very low ecological value to find the best way to connect existing residual natural areas.

\section{Study area}

In 2010, the Lombardy Region adopted the New Regional Landscape Plan (Piano Paesaggistico Regionale). This plan has introduced the green infrastructure network for landscape recovery (Rete Verde di Ricomposizione Paesaggistica): a system of non-urbanised areas (natur- al, agricultural and abandoned areas) that have to be protected and recovered to improve landscape quality, especially in the urban fringe. In line with this document, we have developed a methodology to help to identify this green network that also fulfilled recreational functions. In this paper, the methodology is applied in a validation area close to Milan but it has been developed in such a way that it may be applied at a regional level through the use of the information available in the GIS of the Regional Authority (http://www.cartografia.regione.lombardia.it/ geoportale). The Lombardy region covers an area of approximately $24,000 \mathrm{~km}^{2}$ (approx. $8 \%$ of the land surface of Italy). It is one of the most densely populated regions of Europe with over 400 inhabitants per $\mathrm{km}^{2}$, and more than $12 \%$ of the area contains buildings for residential and production use. The study area is located in northern Italy along the stretch of the river Lambro between Monza and Milan. The river Lambro rises in the foothills of the Lombardy Region near lake Como, crossing the hills of Brianza and the Po valley, and moves downstream $130 \mathrm{~km}$ until it reaches the river $\mathrm{P}$, the largest river in Italy (Figure 1).

The Lambro crosses one of the most densely populated areas in Italy and is consequently one of the Italian rivers that has suffered most from the industrial activities that take place on its banks. For centuries, its waters have powered a large number of mills. Since the nineteenth century, it has been used in textile and metallurgical processing and the polluted water has then been channelled back into the river. In the second half of the twentieth century, the growth of urban areas and the subsequent construction of sewer networks which discharge sewage directly into the Lambro have increased the problem. At the end of the 1980 s, the water of the river Lambro that arrived in Milan was biologically dead because it lacked oxygen and, with the addition of sewage from the east side of the city, it became the main polluter of the river Po and the waters of the Adriatic Sea.

Since the late 1980s, the local authorities have promoted the construction of waste water treatment plants and, in subsequent years, water quality in the river Lambro, evaluated according to the European Union Framework Directive (2000/60/EC) (European Commission, 2000 ), has gone from very bad to poor or sufficient, and values are gradually improving. To complete the process of improving the quality of the river water, favoured by the natural aspect of most of its banks, the riverbed needs to be dredged to remove the pollutants that have settled over time. The results already achieved allow the next phase of reme-
A

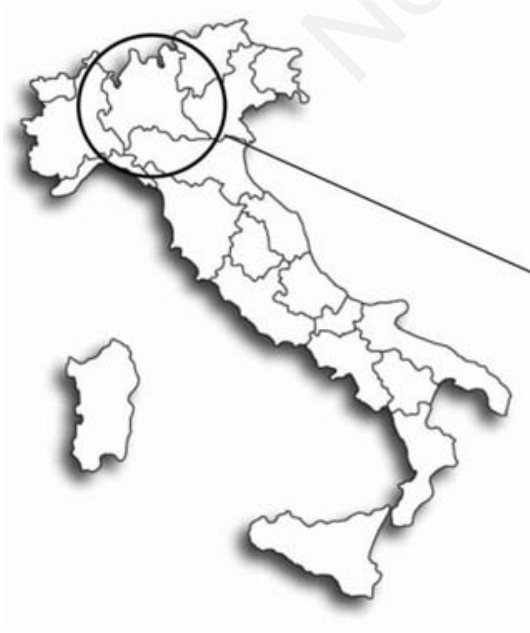

B

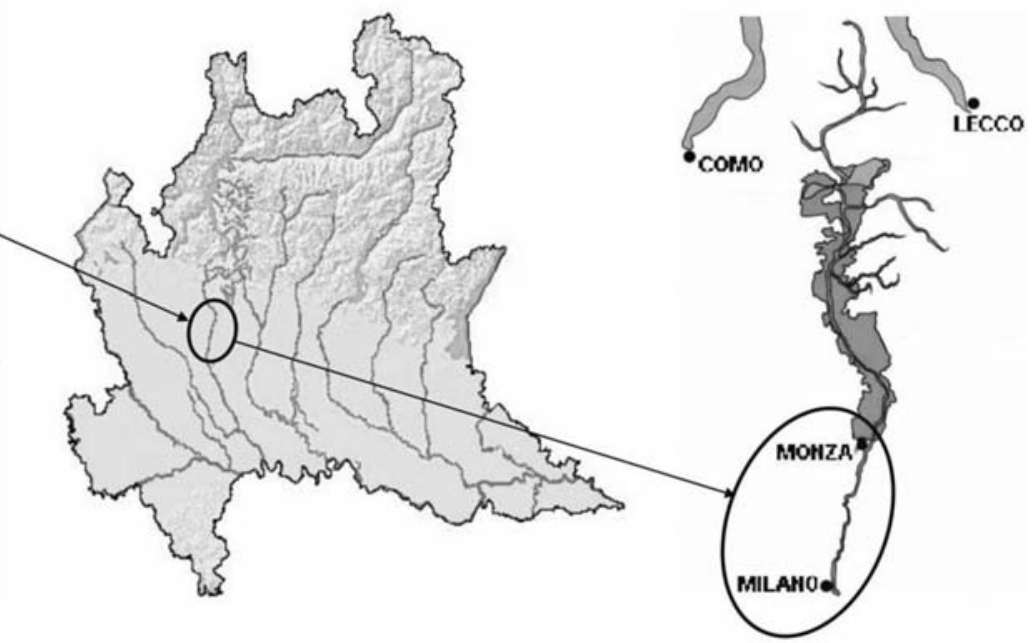

Figure 1. Study area. (A) Italy. (B) The region of Lombardy. (C) The stretch of the river Lambro under study. 
diation to start for the areas along the riverbanks. As mentioned above, they can fulfil both an ecological function (such as in the case of the residual natural areas found in environments that are heavily populated and crossed by numerous transport routes) and a recreational function for the inhabitants living nearby.

The stretch of river examined in this study is that between Monza and Milan, two of the largest cities in northern Italy. The study area starts in Monza's Royal Park (a fenced-off historical park in an area of over 700 hectares), crosses the city centre and outlying areas and the borders between Brugherio, Sesto San Giovanni and Cologno Monzese, before crossing the Lambrate district (which takes its name from the river) in the municipality of Milan and connected to Milan's city greenbelt park system. The total length of the section studied is approximately $22 \mathrm{~km}$ and the analysis covered a wide range of approximately $2.5 \mathrm{~km}$ per side and a total area of approximately $100 \mathrm{~km}^{2}$. The width of the area has been defined using landscape units, identified along the river. Out of this buffer zone, the landscape elements do not depend on the presence of the river. Also, there is no visual perception of the river and its elements (natural vegetation, rows of trees, woods, slopes, etc.).

\section{Materials and methods}

The methodology has been divided into four phases: identification of functions, territorial analysis, resource evaluation and planning (Fumagalli and Toccolini, 2012). The identification of the waterfront functions has been discussed in general terms in the previous section. In detail, the functions that can be fulfilled by waterfronts in suburban areas are: i) to create ecological corridors that enable flora to survive and promote movement of fauna, act as a filter for pollutants destined to reach the water, and help to contain variations in the flow of the waterways; ii) the construction of bicycle paths.

The next phase of territorial analysis consists in defining the context within which the identified functions can be developed. Accordingly, the analysis should be conducted on two levels: i) a framework providing an understanding of the context, i.e. river and other water courses, historical land use, park systems, transport network and current urban planning instruments; ii) detailed information for a precise knowledge of the study area, i.e. land use, vegetation and protected areas, water network, existing bicycle paths.

All these data are available on the GIS of the Regional Authority in vector format. (The description of the data and information is summarised in Table 1).

The third phase is necessary for evaluation of resources. With regard to the ecological function, it is necessary to identify: i) the main origin and destination of existing areas (nodes of ecological network) (1); ii) the axes of connection between them (ecological corridors) (Sigura, 2010) (2).

The areas (1) must be selected on the basis of two criteria (Kong et al., 2010).

- Minimum area required: patch area must be at least 10 ha. Choosing a specific species is a problem at a landscape level, so 10 ha was chosen as a hypothetical minimum area requirement. Kong (Kong et al., 2010) used 12 ha but since the Italian landscape is more fragmentary so it was decided to reduce it by $20 \%$. Large patches are more valuable because they support large, more permanent populations, and the patch area is related to abundance, persistence and diversity of wildlife.

- Location such that it permits connectivity inside the study area and connection with nodes of the ecological network outside the study area. Although this is somewhat arbitrary, it will be helpful to connect green space patches spread all over the study area.

The corridors (2) are achieved by assigning weighting to the study area. These weightings are linked to the difficulties fauna have to overcome to move around land with various uses (impedance values) (Schiller and Horn, 1997; Miller et al., 1998). The ability to move within a given environment is species specific, i.e. different for different species (Collinge, 1996). However, the type of ground cover can be considered the most important factor in determining the possible spread of species. Vegetation coverage and vegetation type determine how natural an area is and, therefore, its suitability for ecological corridors. In addition, impedance values are also indicative of the costs of converting land use in an ecological corridor. Consequently, areas with vegetation are assigned a low impedance value as they offer less resistance to the movement of flora and fauna, and, therefore, have lower transformation costs than built-up areas. Impedance values are assigned to the categories of land use identified above, taking into account the type of vegetation cover and the level of human disturbance (the more disturbance, the more difficult it is for the vegetation to spread) (Guan et al., 2007). Table 2 lists the categories identified and the corresponding values, using those proposed by Kong et al. (2010) and adapted to Italy, considering different land use classification.

With reference to the recreational function, the distribution of paths and the level of connection between existing and planned pedestrian and bicycle paths has been evaluated. This was carried out by: i) using network analysis to exclude unconnected paths; ii) creating a buffer zone (150 $\mathrm{m}$ radius, i.e. a distance covered in $2 \mathrm{~min}$ by bike) along existing and planned paths to measure the distance of the paths from the waterfront.

Table 1. Dataset and information useful for resource analysis and assessment.

\begin{tabular}{|c|c|c|c|}
\hline Name & Description & Scale & Update \\
\hline Hydrological network & Natural and artificial water system & $1: 10,000$ & 2012 \\
\hline Road network & Road, rail, underground and other transportation systems & $1: 10,000$ & 2012 \\
\hline Park system & National, regional and local natural park & $1: 10,000$ & 2012 \\
\hline Landscape evolution & Historical land use & $1: 25,000$ & $1950 / 1980$ \\
\hline Regional Landscape Plan & Ecological network, green network & $1: 50,000$ & 2010 \\
\hline Water use and protection plan (PTUA) & Water characteristics, flood areas, water discharges, water treatment plant & $1: 25,000$ & 2006 \\
\hline Hydrological plan (PAI) & Protected areas along rivers & $1: 10,000$ & 1989 \\
\hline Provincial plan (PTCP) & Ecological network elements & $1: 25,000$ & 2003 \\
\hline Municipal plan (PGT) & Existing and planned bicycle paths & $1: 10,000$ & $2010 / 2012$ \\
\hline Land use & Land use classified using Corine Land Cover classification & $1: 10,000$ & 2009 \\
\hline
\end{tabular}


In the final planning phase, in order to identify the ecological corridors, network analysis was used to find the best connections between the nodes of ecological network, based on the land use of the areas crossed and the length of the connections. This enabled the cost of transforming the areas crossed to join up with the nodes of the ecological network to be evaluated (Tan, 2006; Zhang, 2006).

This occurs through the conversion of land use into raster format dividing the area into cells of dimensions congruent to the scale of intervention, the level of detail of the information available, and the minimum size necessary for the creation of ecological corridors. The cell dimension used for rasterisation is $40 \times 40 \mathrm{~m}$, equal to the minimum mappable area on available land use maps.

The direction and width of the corridors are identified taking into account the use of the land that the corridors cross. Where land use permits, the ecological corridors should be widened, beyond the size of the cell that is crossed, in order to increase efficiency (Thoren, 2000).

In detail, the cost distance (CD) analysis determines the shortest weighted distance (accumulated travel cost) from each cell to the nearest source location.

The CD creates raster data in which each cell is assigned the accumulative cost to the closest source cell. The algorithm utilises the nodelink cell representation used in graph theory (each centre of a cell is considered a node and each node is connected to adjacent nodes by multiple links).

Every link is given an impedance value. This is derived from the costs associated with the cells at each end of the link (from the cost surface) and from the direction of movement through the cells. The cost assigned to each cell represents the cost per unit of distance covered to move through the cell.

Different types of output from the cost distance analysis are identified: i) back link cost: gives a raster that identifies the direction or the next neighbouring cell to take from any cell to the nearest source. The algorithm assigns a number from 0 to 8 to each cell: 0 represents the source locations, 1-8 encode the direction in a clockwise manner starting from the right. If the path is to pass into the neighbouring cell on the right, the cell will be assigned the value 1,2 for the lower right diagonal cell, and so on continuing clockwise; ii) least cost path: calculates the least cost path from a source to a destination. The algorithm produces an output raster that records the least cost path from selected locations to the closest source cell defined within the accumulative cost surface, in terms of cost distance.

The least-cost path function is a raster-based optimisation algorithm originally designed to find the least expensive path for a road between two points using cumulative-cost surface constructed outward in all directions from the destination. This function can be useful to apply to identify habitat linkages to maintain or restore ecological connectivity. Using ArcGis, the cost distance functions are applied to calculate cumulative cost surface (functions of the classes of use crossed) with cost back link to identify the directions of movement and, finally, the least cost path to identify connecting paths (Kong et al., 2010). Starting from the vector map of land use, we proceeded with its rasterisation based on one cell that was $40 \times 40 \mathrm{~m}$, a size consistent with the scale of intervention and the level of detail of the information available.

Once the functional diagram and values of impedance classes are defined, the processing performed so far is substantially automatic and, therefore, can be easily and quickly carried out using ArcGIS tools.

The criticality of the corridors generated by functions applied was then highlighted, criticality represented by the crossing of cells for land use incompatible with the creation of ecological corridors: built up areas, transport routes, and areas of water. Major criticality presents itself when the corridors cross major transport routes (motorways, railways, subways) and areas of water. The resolution of these critical

Table 2. Land use classification and impedance values assigned.

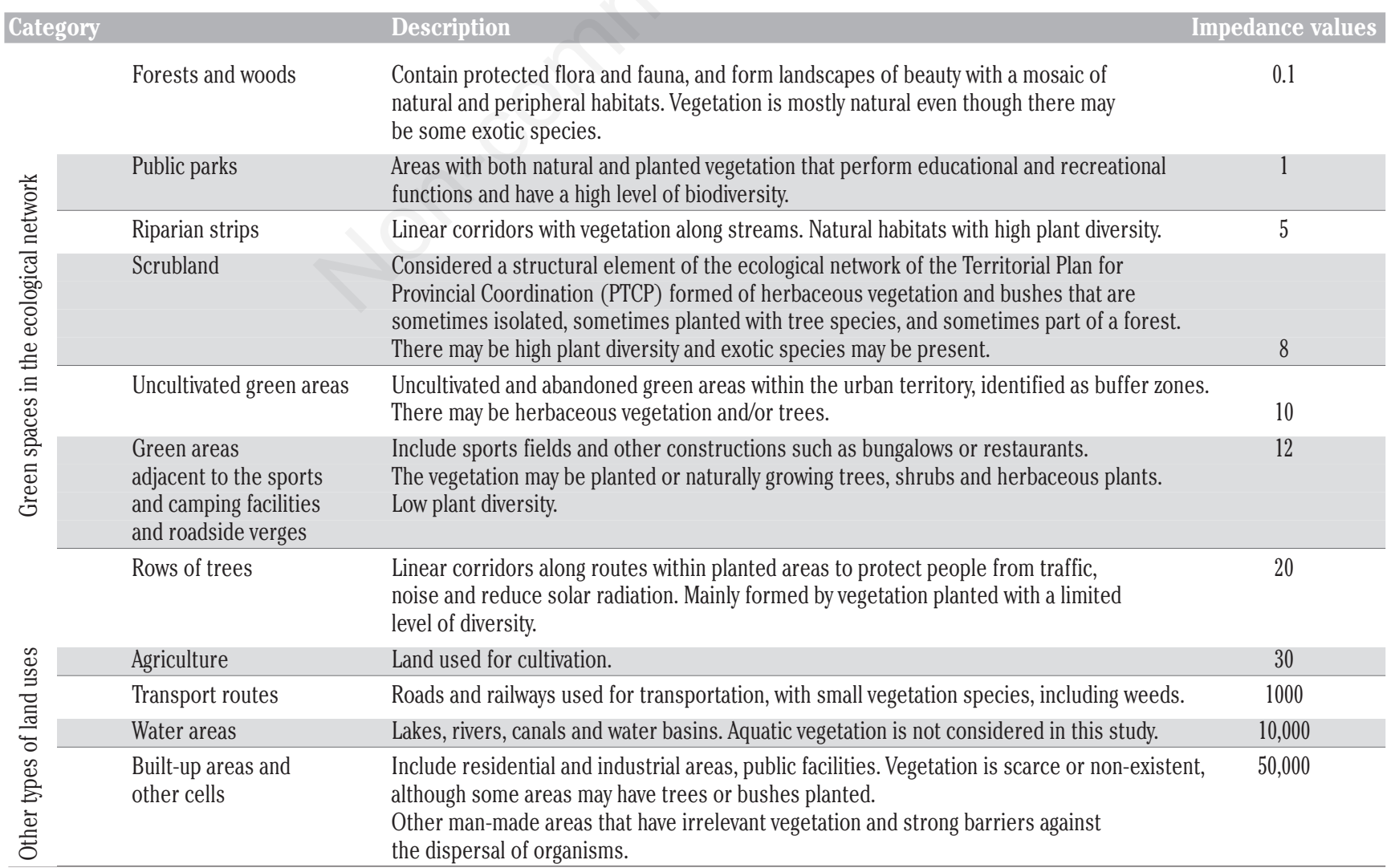


points is passed through direct survey, to identify alternative corridors, also using areas with vegetation, that have a smaller surface area to the minimum land use unit mapped (40 m wide) or using linear elements (rows of trees and hedges). The network of paths is proposed, taking into account elements of existing bicycle paths or bicycle paths planned by urban instrument plans (Smith and Hellmund Cawood, 1993). According to Turner (Turner, 2006) criteria used for constructing cycle paths along suburban waterfronts are: i) using the axis of the river as the main axis direction to follow; ii) ensuring the highest level of continuity with the visual and auditory elements of water (one of the most important requirements for the construction of the waterfront); iii) integrating existing and planned bicycle paths. Finally, other recreational activities have been located while taking into account the impact they have on the natural environment and based on their distance from the bicycle access paths.

\section{Results and discussion}

The river flows through a heavily urbanised area: land used for residential and production purposes accounts for over $50 \%$ of the territory, followed by areas of arable land (20\%), parks and gardens (8\%), and numerous transportation routes (motorways, railways, underground trains) that intersect at various points along the course of the river (Figure 2). There are also two artificial canals, the Villoresi and Martesana waterways, crossing the river in an east-west direction, with two canal bridges that can be used to channel excess water into the river in order to regulate water flow in the canals during flooding events. The old towpaths and greenways are now fully restored along these canals, and these intersection points are undoubtedly essential elements for connecting the network of greenways of the Lombardy

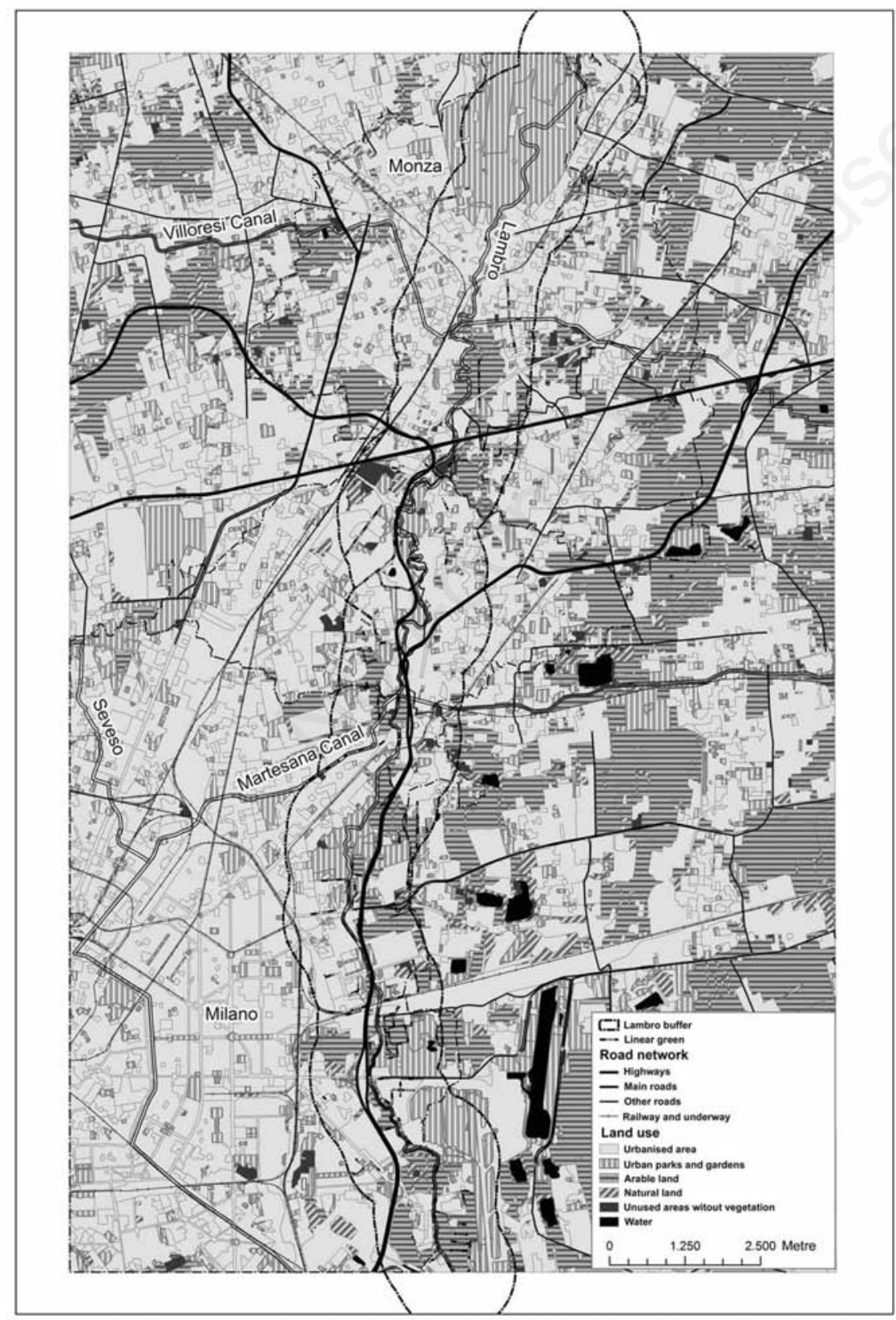

Figure 2. Land use map. 
Region, allowing inhabitants to gain easier access to green areas. Finally, the existence of protected areas that are both regional (Lambro Valley Regional Park, Milan South Park) and inter-municipal (Lambro Middle Valley Park, Pioltello Farmhouses Park, East Quarries Park, and others) will help conserve indigenous flora and fauna, and increase interest in the study area (Zonneveld, 2007).

For the analysis phase, Figure 3 summarises the procedural steps followed to define ecological corridors and recreational functions that the waterfront can perform (see above). To define the ecological corridors, the classes with natural vegetation are extracted from the land use map (scale 1:10.000, up-dated and down-loaded from the Lombardy region GIS, 2009).

Based on the abovementioned requirements, eight areas were selected, covering a minimum of 10 hectares, distributed in order to cover the entire study area and connected with other sections of the ecological network in the area. This has allowed the preparation of a functional diagram illustrating the ecological nodes of the network and directional axes of connection between them (Linehan et al., 1995) (Figure 4).

The cost distance function (Figure 5) has provided a map as output with 10 interval value classes and the lowest class must be further exploited for the creation of the ecological network. The classes with the lowest values (colours from white to light grey) correspond to the areas with vegetation, as they have low impedance values, while those with the highest values (colours from grey to dark grey) correspond to areas with buildings, since they have higher impedance values. Agricultural areas are in the middle of the scale. The nodes are in black.

The back link cost defines the neighbour that is the next cell on the least accumulative cost path to the nearest source. It has been applied to identify the directions for connection between the nodes of ecological network of two areas considered strategic, as they represent the points of intersection of the corridors identified in Figure 4. In this way, it was possible to create a linear connection along the course of the river and two axes for transverse connection, starting from the nodes of the ecological network placed along the nearest river (Figure 4).

The Cost Path tool determines the least-cost path to connect nodes. The Cost Path tool uses two rasters derived from a cost distance tool: the least-cost distance and back link raster. These rasters are created from the CD or Path Distance tools. The back link raster is used to retrace the least costly corridor between nodes.

Using the two maps produced in this way, the least cost path (function of distance and cost) has been applied for destination pairs in order to identify the optimal paths, taking into account the cumulative cost of moving and the directions to follow, ensuring the least implementation cost (Figure 6). Seven possible ecological corridors were identified in this way: for each corridor, the start coincides with the point within the departure area that has the lowest cost distance and it expands in the directions indicated by the cost back link, crossing the areas that offer the lowest cumulative cost once they arrive at their destination in the second ganglion.

Corridors identified in this way have no width. Therefore, the final phase was to assign them a width based on the bibliographic analysis. Given the extreme fragmentation and the high degree of urbanisation of the area, where the use of the land permits, a width of $40 \mathrm{~m}$ was given. Of the approximately $43 \mathrm{~km}$ of potential ecological corridors identified, approximately $60 \%$ have a width of at least $40 \mathrm{~m}$. The points where the corridors are not extended coincide, however, with the roads or urbanised areas crossed, classified as having no vegetation in the land use map. Direct survey, the use of aerial photography, and the census of the rows of trees has allowed the identification of smaller areas of vegetation that can still be used to expand the ecological corridors often in connection with residual agricultural areas, using mainly minor stretches of vegetation along the roads (Viles and Rosier, 2001). The path of the potential ecological corridors is shown in Figure 7.

The definition of connecting bicycle paths between Monza and Milan is primarily chosen to ensure, on the one hand, the continuity of visual and auditory water elements, which serve no purpose other than to represent an axis of reference for the construction of the path, and on the other, connection between towns located along the axis (Toccolini et al., 2004; Senes et al., 2010). Those people who will enjoy the resources provided by the path come from the towns. From the analysis of the map of land use, the major residential areas were extracted to identify areas to connect and define the functional diagram of the cycle path ( $\mathrm{Al}$ hagla, 2010) (Figure 3).

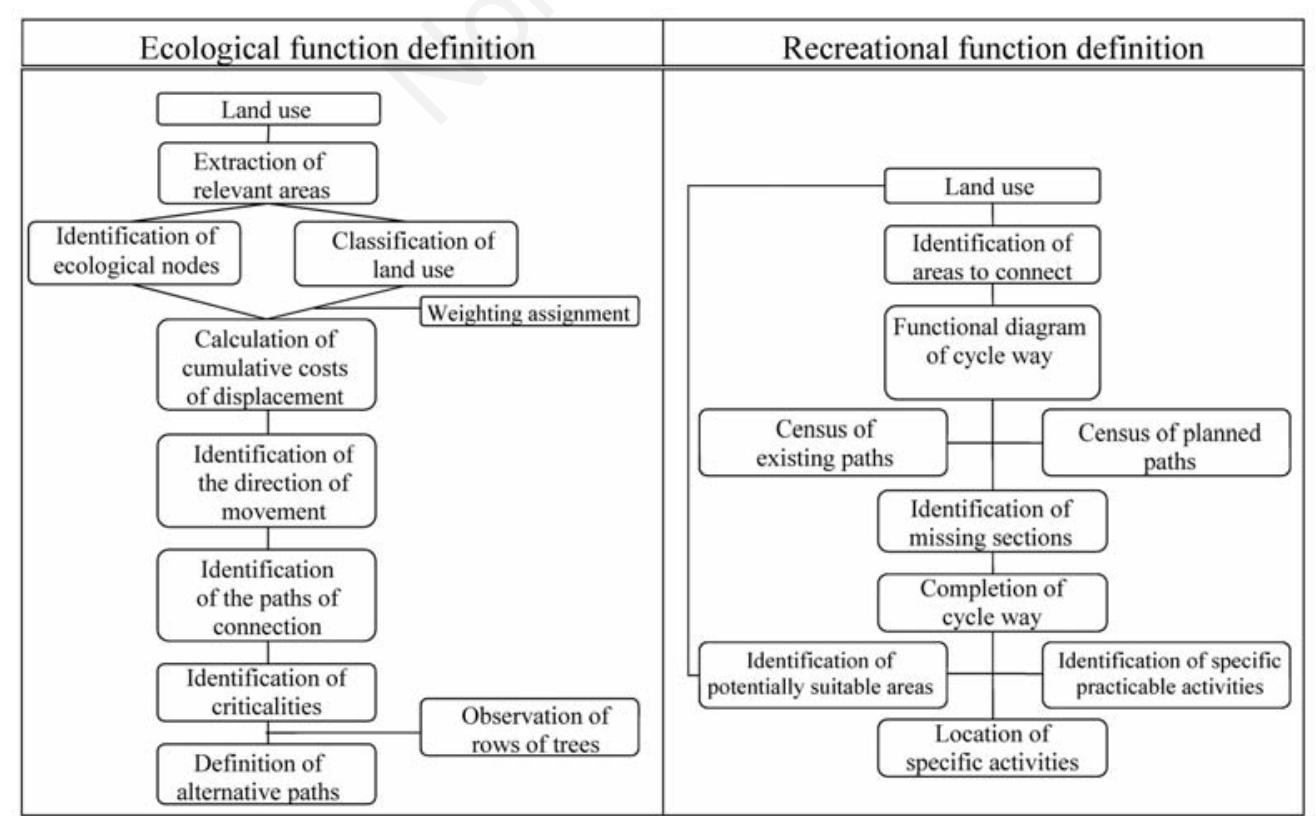

Figure 3. Procedural steps followed for the definition of the ecological and recreational functions. 
The GIS was used to collect data about existing and planned paths. The buffer zone created along the trail allowed paths to be selected along the river. The binary model of network analysis determined the level of connection.

In this way, it was possible to identify the missing paths, amounting to approximately $3 \mathrm{~km}$ of a total of approximately $17 \mathrm{~km}$ needed to complete the track (of which the majority, almost $9 \mathrm{~km}$, have been scheduled). The path proposed (Figure 7) starts from Monza Park and ends at Forlanini Park in Milan. At times, it runs alongside the identified ecological corridors. However, this is not an issue, since cycling activities use self-contained lanes and, since they have a low impact on their surroundings, they cause no major disturbance to the natural environment. Due to its length and location, the path appears to be extremely functional for everyday use, for commuting from home to work and school, and for access to parks and other areas of natural and recreational value.

Unfortunately, the path identified does not always ensure visual continuity with water because of the highly urbanised and industrialised environment that has developed along the river (which prevents appropriate approach routes) and the decision to use existing and planned bicycle paths. Moreover, it is important to emphasise that the identified path, crossing densely urbanised areas, may represent an important

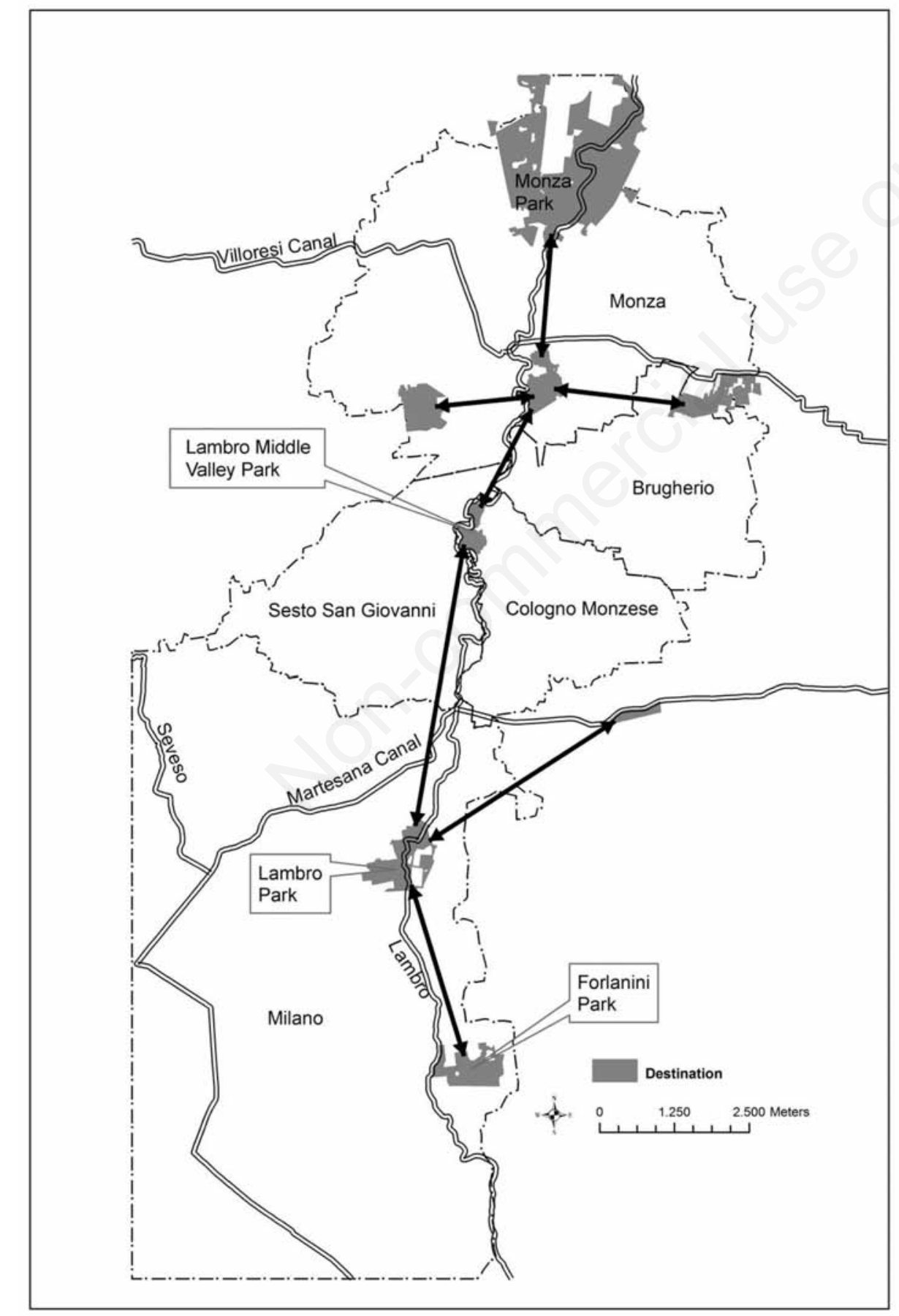

Figure 4. Functional layout. 


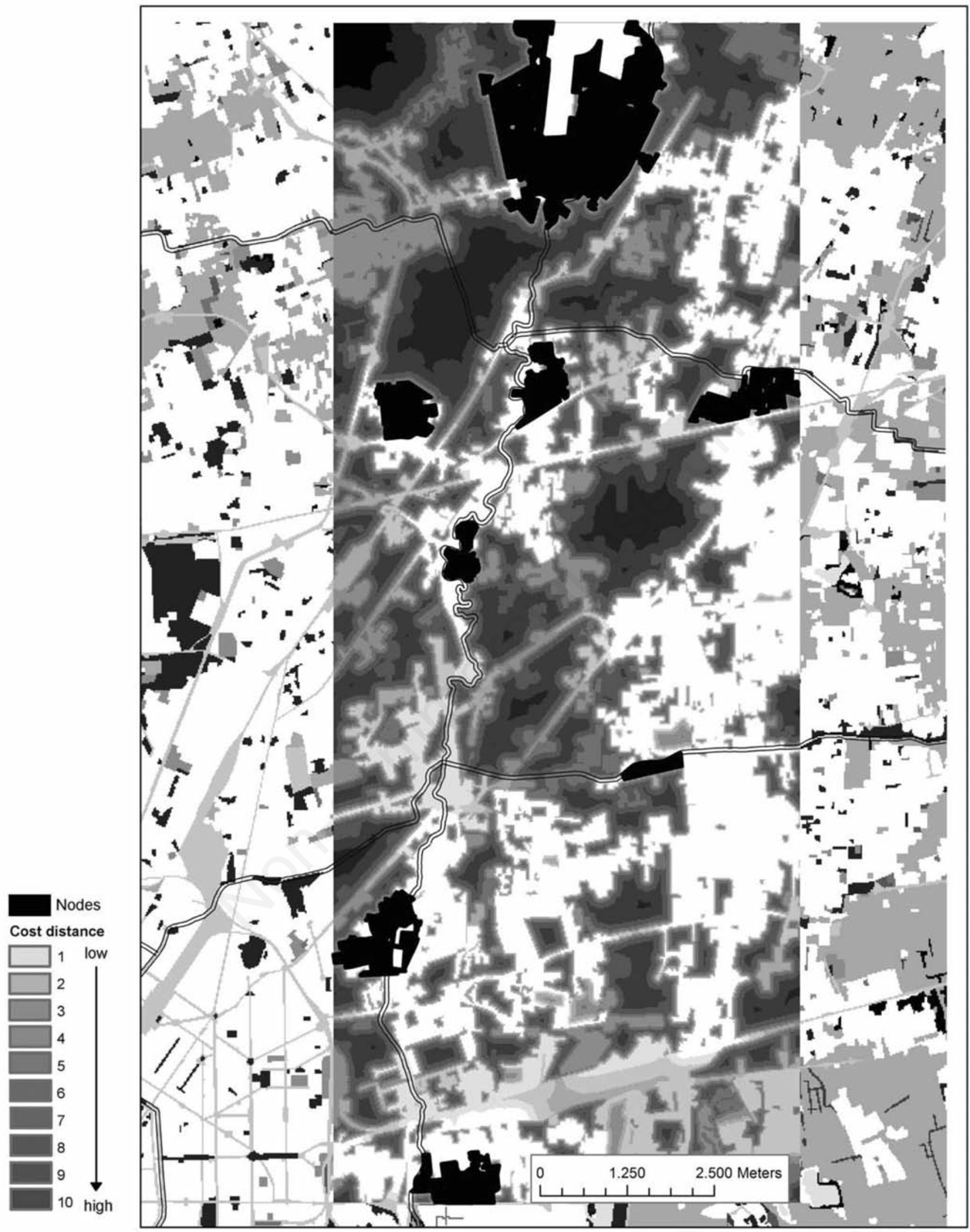

Figure 5. Identification of cumulative costs of displacement through the application of the cost distance function. 


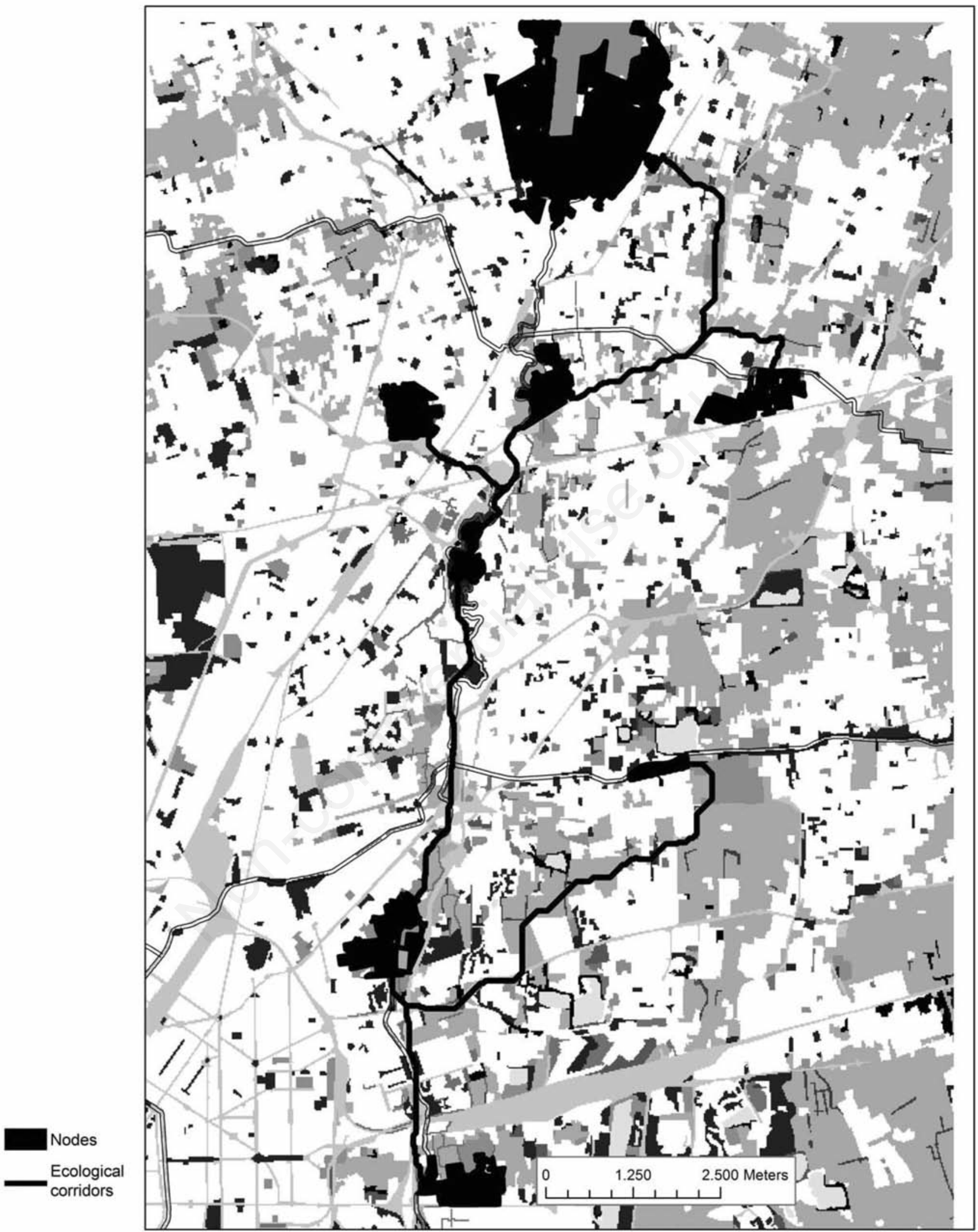

Figure 6. Identification of ecological corridors through the application of the least cost path function. 
route for daily commuting from home to work and school, as well as for leisure time use (Toccolini et al., 2006). Furthermore, they connect with other important greenways, such as the Martesana Waterway towpath and the Villoresi Canal, giving greater value to the remaining rural areas and historical buildings along these paths.

Due to the poor water quality in this stretch of the river Lambro, it was not thought useful to identify points where the water can be accessed for aquatic activities. Only good water quality [defined according to the criteria of the European Union Framework Directive, 2000/60/EC (European Commission, 2000)] is conducive to bathing, fish life and, therefore, fishing. Since canoeing involves water contact, it was decided for now to exclude this type of activity and not identify points where the water can be accessed.

For the development of other recreational activities along the waterfront, two criteria are considered: the impact they have on the natural environment and the distance of the bicycle pathways identified as routes for preferential access. Recreational activities carried out on land (camping and sports) require the presence of specific equipment (such as fields, nets, gates, baskets, race tracks, bridges, places for tents, toilets, bungalows, etc.). The areas selected to develop and carry out sports and camping activities have been extracted from the map of land use in consideration of three categories: public gardens, camping and sports facilities. These areas are well distributed along the bicycle paths and offer a wide variety of options for different indoor and outdoor sports.

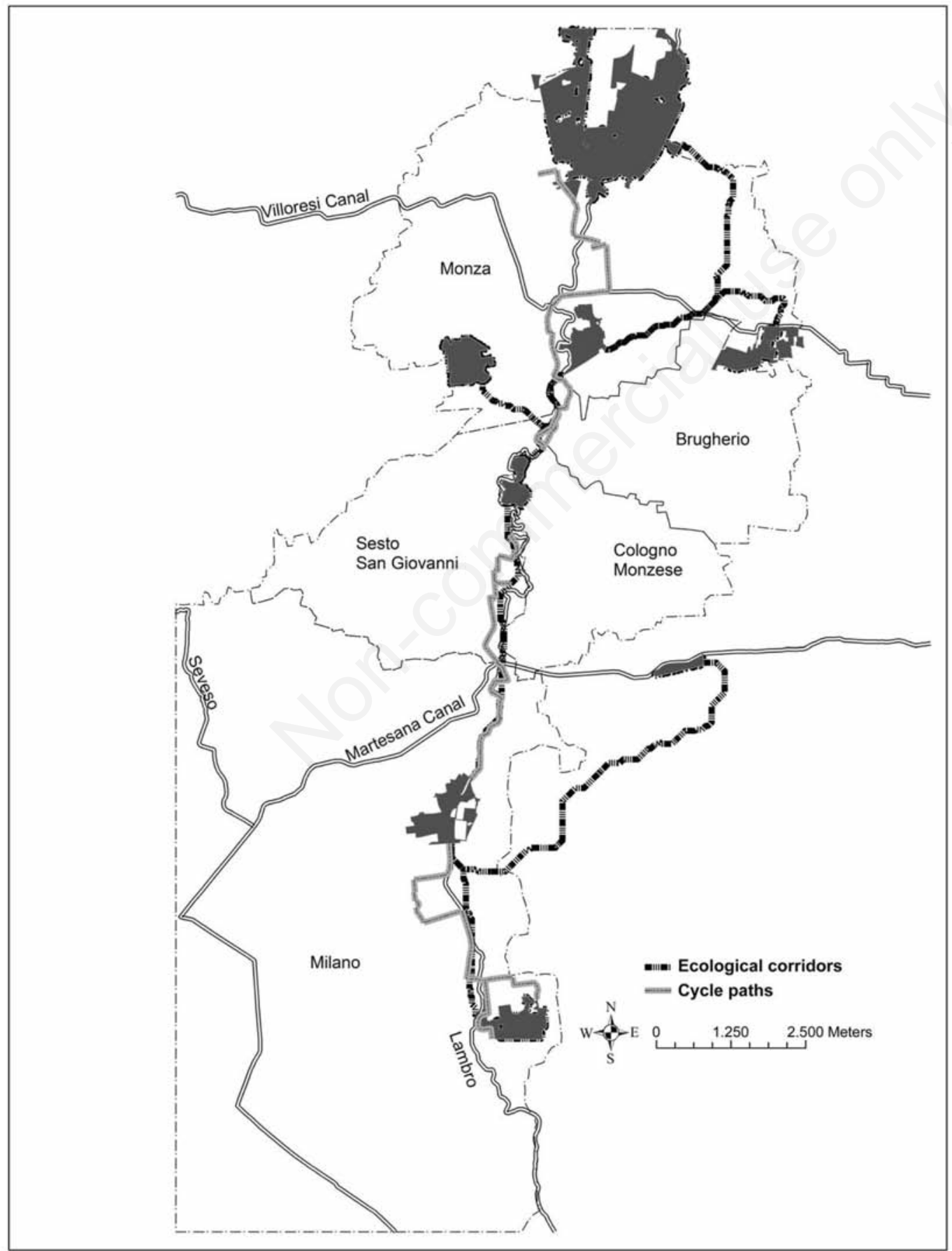

[page 150]
Figure 7. Ecological corridors, and bicycle paths, identified for the construction of the waterfront of the river Lambro. 
To ensure user comfort and promote contact with Nature, parking and picnic areas are to be constructed within those areas with vegetation. These functions do not have a significant impact on natural resources and it has been found that, as well as in parks and gardens, they can also be located in sports and camping facilities where other activities are carried out (thus avoiding constant displacement), and in areas with more natural vegetation (such as forests, areas with low vegetation, uncultivated green areas and riparian vegetation), located along existing, scheduled and new bicycle paths. These areas should not be too far from the bicycle paths in order to facilitate their identification and easy access, and they should not be too far apart so as not to cause inconvenience (e.g. insufficient places for rest and refreshment, essential in the warmer months for user safety and welfare). Therefore, it was decided in this study to identify a $20 \mathrm{~m}$ buffer zone and locate it in the immediate vicinity of bicycle paths, compatible with the resolution of the map of land use, within which the areas of vegetation described above are identified. These areas are mainly (over $50 \%$ ) located in public parks and gardens in areas with riparian vegetation (i.e. in close contact with the river, 27\%) and in areas designated for sporting activities (i.e. connected to other structures with a recreational function). Parking areas are also well distributed along the waterfront.

In summary, the application of the methodology to the study area has identified approximately $40 \mathrm{~km}$ of potential ecological corridors, over half of which are over $40 \mathrm{~m}$ wide, and a pedestrian and bicycle path connecting Monza Park to Forlanini Park in Milan $16.80 \mathrm{~km}$ long, of which $3.6 \mathrm{~km}$ is new, $8.4 \mathrm{~km}$ scheduled, and $4.8 \mathrm{~km}$ already existing.

\section{Conclusions}

The redevelopment of the Lambro waterfront, necessarily associated with an improvement in the quality of its water, may be an important opportunity to create a connecting green axis between Monza Park and the city parks on the eastern side of Milan (Lambro Park and Forlanini Park) of anthropic (recreational and access links) and natural value. The methodology is already used for ecological planning on a larger scale and in areas with a higher environmental value (Kong et al., 2010) and has confirmed its validity even for areas that are heavily urbanised and on a more detailed scale than those characterised by the existence of a watercourse.

Firstly, this has allowed potential corridors based on current land uses to be quickly identified thus clearly defining the areas of land required to establish ecological networks, and, secondly, it has addressed the issue of the pedestrian and bicycle paths on a larger scale, beyond the municipal context. Both aspects are of considerable importance for Europe, and for Italy in particular, given that, in this country, defined sections of territory are often governed by several different town councils (Jongman et al., 2004). The ecological network is usually planned at a regional and at a provincial level with the approximate identification of the connecting axes and corridors. There is not enough detailed information available to be able to include these corridors into municipal level planning. The proposed methodology is useful to identify precisely which areas can be included in these corridors. The selected areas will be protected by municipal planning legislation.

On the other hand, the issue of pedestrian and bicycle paths is often addressed only within the individual municipalities, focusing on connecting city centres and outlying areas, and neglecting the importance of the link between the various towns themselves. Associating an ecological with a recreational function allows the network of bicycle paths to be planned on a larger scale (Little, 1990).

The validity of the results is significantly linked to the availability of sufficiently detailed and up-dated information relating to land use: an up-dated land use map at 1:10.000 scale is sufficient together with detailed aerial photographs. The methodology is parameterised so that it may be as objective as possible. With this in mind, the discretionary phase for identifying classes of impedance and assigning weighting to the corresponding land uses can be said to be sufficiently consolidated in the existing literature (Collinge, 1996; Schiller and Horn, 1997; Miller et al., 1998; Guan et al., 2007; Kong et al., 2010).

In summary, on the basis of highly detailed initial information and using a number of available analytical functions, a waterfront can be planned in detail such that direct mapping will only be required to identify criticality solutions. The methodology can be consolidated through integration of the analysis and planning phases to evaluate the hydrological function of the waterfront (contributing to the improvement of water quality, hydrological regulation and control of water temperature) and the inclusion of those aquatic activities (fishing, canoeing and swimming) that, due to poor water quality, were not considered in the current report.

\section{References}

Ahern J. 1995. Greenways as a planning strategy. Landscape Urban Plan. 33:131-55.

Al-hagla K.S. 2010. Sustainable urban development in historical areas using the tourist trail approach: A case study of the Cultural Heritage and Urban Development (CHUD) project in Saida, Lebanon. Cities 27:234-48.

Baschak L.A., Brown R.D. 1995. An ecological framework for the planning, design and management of urban river greenways. Landscape Urban Plan. 33:211-25.

Ben Harman B., Low Choy D. 2011. Perspectives on tradable development rights for ecosystem service protection: lessons from an Australian peri-urban region. J. Environ. Plan. Manage. 54:617-35.

Breen A., Rigby D. 1997. Waterfront, city reclaim their edges. McGraw The waterfront press, Washington, DC, USA.

Bueno J.A., Vassilios A.T., Alvarez L. 1995. South Florida greenways: a conceptual framework for the ecological reconnectivity of the region. Landscape Urban Plan. 33:247-66.

Bunce S., Desfor G. 2007. Political ecologies of urban waterfront transformations. Cities Int. J. Urban Policies Plan. 24:251-334.

Bunn AG., Urban D.L., Keitt T.H. 2000. Landscape connectivity: a conservation application of graph theory. J. Environ. Manage. 59:265-78.

Collinge S.K. 1996. Ecological consequences of habitat fragmentation: implications for landscape architecture and planning. Landscape Urban Plan. 36:59-97.

European Commission, 2000. Directive 2000/60/EC of the European Parliament and of the Council of 23 October 2000 establishing a framework for Community action in the field of water policy. Official Journal L 327, 22/12/2000, pp 1-73.

Fisher B., Gordon L.A.D., Holst L., Krieger A., McMillan G., Rafferty L., Schiffman E.S. 2004. Remaking the urban waterfront. Urban Land Institute, Washington, DC, USA.

Flink C.A., Searns R.M. 1993. Greenways: a guide to planning, design and development. Island Press, Washington, DC, USA.

Fumagalli N., Toccolini A. 2012. Relationship between greenways and ecological network: a case study in Italy. Int. J. Environ. Res. 6:903-16.

Guan Z.L., Huang Y.X., An Y.N. 2007. Landscape ecological comprehensive assessment of urban greenland system in Ningde City. J. Fujian Forest. Sci. Technol. 3:760-5.

Jongman R.H.G., Külvik M., Kristiansen I. 2004. European ecological networks and greenways. Landscape Urban Plan. 68:305-19. 
Kong F., Haiwei Y., Nobukazu N., Zong Y. 2010. Urban green space network development for biodiversity conservation: identification based on graph theory and gravity model. Landscape Urban Plan. 95:16-27.

Linehan J., Gross M., Finn J. 1995. Greenway planning: developing a landscape ecological network approach. Landscape Urban Plan. 33:179-93.

Little C.E. 1990. Greenways for America. The Johns Hopkins University Press, Baltimore, MD, USA.

Miller W., Collins M.G., Steiner F.R., Cook E., 1998. An approach for greenway suitability analysis. Landscape Urban Plan. 42:91-105.

Regione Lombardia, 2010. Piano Paesaggistico Regionale. Regione Lombardia, Milano, Italy.

Schiller A., Horn S.P. 1997. Wildlife conservation in urban greenways of the mid-southeastern United States. Urban Ecosyst. 1:103-16.

Senes G., Fumagalli N., Toccolini A. 2010. Urban greenways planning. A vision plan for Milan (Italy). Proc. Fábos Conf. on Landscape and Greenway Planning 2010, Budapest, Hungary.

Senes G., Toccolini A., Ferrario P.S., lafortezza R., Dal Sasso P.. 2008. Controlling urban expansion in Italy with green belts. In: M. Amati (ed) Urban green belts in the 21th century. Ashgate, Aldershot, UK, pp 203-225.

Sigura M. 2010. Rural landscape multifunctionality: a GIS based approach for assessing areas characterized by ecological functions. J. Agric. Eng. 41:29-36.

Smith D.S., Cawood Hellmund P. 1993. Ecology of greenways: design and function of linear conservation areas. University of Minnesota Press, Minneapolis, MN, USA.

Tan K.W. 2006. A greenway network for Singapore. Landscape Urban
Plan. 76:45-66.

Thoren K.H. 2000. "The green poster" A method to evaluate the sustainability of the urban green structure. Environ. Impact Assess. Rev. 20:359-71.

Toccolini A., Fumagalli N., 2007. Greenway e reti ecologiche: sinergie e conflittualità. Estimo e Territorio LXX-12:49-62.

Toccolini A., Fumagalli N., Senes G. 2004. Manuale per la progettazione dei percorsi verdi. Maggioli Editore, Rimini, Italy.

Toccolini A., Fumagalli N., Senes G. 2006. Greenways planning in Italy: the Lambro River Valley greenways system. Landscape Urban Plan. 76:98-111.

Turner T. 1998. Landscape planning and environmental impact design. UCL Press, London, UK.

Turner T. 2006. Greenway planning in Britain: recent work and future plans. Landscape Urban Plan. 76:240-51.

Urban D., Keitt T. 2001. Landscape connectivity: a graph-theoretic perspective. Ecology 82:1205-18.

Viles R.L., Rosier D.J. 2001. How to use roads in the creation of greenways: case studies in three New Zealand landscapes. Landscape Urban Plan. 55:15-27.

Zetterberg A., Mörtberg U., Balfors B. 2010. Making graph theory operational for landscape ecological assessments, planning and design. Landscape Urban Plan. 95:181-91.

Zhang L., Wang H. 2006. Planning an ecological network of Xiamen Island (China) using landscape metrics and network analysis. Landscape Urban Plan. 78:449-56.

Zonneveld W. 2007. A sea of houses: preserving open space in an urbanised country. J. Environ. Plan. Manage. 50:657-75. 